\title{
ARE NANOMATERIALS POTENTIAL NEW GENERATION ANTIMICROBIAL FEED ADDITIVES IN LIVESTOCK?
}

\author{
A. K. PATRA \\ Department of Animal Nutrition \\ West Bengal University of Animal and Fishery Sciences \\ 37 K. B. Sarani, Belgachia, Kolkata- 700 037, India
}

\begin{abstract}
Ban and restriction of in-feed antibiotics for farm animals due to potential emergence of antibiotic resistant pathogenic microorganisms have led to search newer antimicrobial feed additives. Recently, various nanomaterials have been tested for antimicrobial actions on the pathogenic microorganisms including antibiotic resistant bacteria. They have also been investigated as antimicrobial feed additives in animals with a purpose to replace antibiotics in feeds. Nano-minerals that are essential for the animals have been explored as mineral supplements as well as antimicrobial effects offering dual advantages in nutritional science. Besides nano-essential minerals, other nanomaterials such as silver, gold, carbon, titanium and silica nanoparticles have antimicrobial properties in vitro conditions and in the gut. This review discusses the antimicrobial effects, especially on the gut microbiota, of different nanomaterials, their mechanism of actions and toxicity with the aim to be used as antimicrobial feed additives in farm animals.
\end{abstract}

Key words: Antimicrobial, Feed additive, Gut, Livestock, Nanoparticle

The use of in-feed antibiotics for farm animals has been banned, restricted or is under scanner due to possible emergence of antibiotic resistant pathogenic microorganisms and residuals in foods (Patra et al., 2019a). Many alternatives such as plant secondary compounds, probiotics, prebiotics and antimicrobial peptides have been investigated as antimicrobial growth promoters to improve growth performance and nutrient utilization in livestock (Patra, 2018). Recently, various nanomaterials have been tested for antimicrobial actions on the pathogenic microorganisms including antibiotic resistant bacteria. Because of their antimicrobial effects, they are also investigated as antimicrobial feed additives in animals with a purpose to replace antibiotics in feeds.

Nanomaterials have been explored for several beneficial uses in different industrial sectors such as electronics, automobiles, biomedical, food packaging and nutritional applications over the past few decades (Ahmed et al., 2016; Gopi et al., 2017). In livestock sectors, nanomaterials are investigated for potential uses in therapeutics, diagnostics, food preservation, antimicrobial feed additives and mineral 
supplements (Gopi et al., 2017; Patra and Lalhriatpuii, 2019). Among the several uses of nanomaterials, they have also been investigated as antimicrobial feed additives. Nano-feed substances could help in increasing the feed proficiency and production performance, diminishing feed cost, and expanding the yield and value of animal products (Gopi et al., 2017; Patra and Lalhriatpuii, 2019).

Among the various types of nanomaterials, nano-minerals could be more bioavailable because of their greater surface area, smaller size and altered properties along with different uptake mechanisms decreasing antagonistic effects among the bivalent cations (Patra and Lalhriatpuii, 2019). In this context, recently several studies have been conducted to evaluate nano-forms of essential minerals as mineral supplements for growth performance and other nutritional evaluations in livestock animals (Patra and Lalhriatpuii, 2019). Therefore, nano-minerals could serve both purposes of antimicrobial feed additives and mineral supplements. Besides nano-essential minerals, other nanomaterials such as silver, gold, carbon, titanium and silica nanoparticles (NP) have shown to exert antimicrobial properties, mostly in the in vitro conditions. There are only few experimental studies on the interaction between nanomaterials and gut microbiome/ microbiota; however available data suggest that nanomaterials may modulate gut microbiome by directly inhibiting the growth of micro-organisms, or altering their metabolic functions in the gut. These functions of the nanomaterials may be suitable to utilize as antimicrobial growth promoters in livestock. This review focuses on the use of nanomaterials for their antimicrobial effects, especially on the gut microbiota in animals.

\section{An overview of nano-materials}

Nanomaterials have a size of less than 100 $\mathrm{nm}$ at least in one dimension with nanoparticles having sizes less than $100 \mathrm{~nm}$ in three dimensions (ISO, 2015). Naturally, nano-particles can occur in ashes and as soil particles or biomolecules, but they are also synthesized using different techniques (Tiede et al., 2008; Patra and Lalhriatpuii, 2019). Engineered nano-materials are synthesized by physical, chemical and biological methods. Physical methods (e.g., high energy ball milling, vapour deposition, electric arc discharge and ultrasonic field) of nano-materials preparation may result in greater nano-materials recovery and absence of residual contaminations (Patra and Lalhriatpuii, 2019; Swain et al., 2015). The chemical syntheses (such as forming colloids and sol-gels) produce nano-materials with uniform sizes, greater stabilization from agglomeration and controlled production rate (Swain et al., 2015; Patra and Lalhriatpuii, 2019). The size of the nanomaterials in the chemical synthesis depends upon the reduction capability of reagents with stronger agent producing smaller particle size in a faster rate (Swain et al., 2015; Patra and Lalhriatpuii, 2019). Stabilizing (e.g., acetate, amines, phosphines and thiols) and surfactant agents (e.g., cyclodextrin, citrate, polyvinyl pyrrolidone and quaternary ammonium salts) stabilize the nano-materials from agglomeration and control particle size formation, prevent aggregation of the produced nano-materials 
and allow nano-materials solubility in various solvents (Yang et al., 2004; Swain et al., 2015; Patra and Lalhriatpuii, 2019). However, chemical methods of nanomaterials synthesis may cause toxicity since hazardous chemicals are utilized during chemical synthesis (Swain et al., 2015). The biological methods utilize microorganisms, fungi, algae, plant extracts containing active molecules, and proteins (usually referred as green synthesis, which uses naturally occurring non-toxic reductants) and other biological materials (i.e, ferritin) for NP synthesis (Ahmed et al., 2016; Mittal et al., 2013).

Nanoparticles exhibit unique physical, chemical and biological properties, such as changes in material strength, solubility, conductivity, optical properties, thermal behavior and catalytic activity, compared to their larger particle sizes (Tiede et al., 2008; Patra and Lalhriatpuii, 2019). Also, nano-materials have higher ratio of surfaceto-volume and proportion of atoms at the surface, which determine their predominant properties of nano-materials (Tiede et al., 2008; Patra and Lalhriatpuii, 2019). The structures and properties of the surfaces of nano-materials are markedly altered due to relatively greater curvatures and edges at the surfaces, higher catalytically active sites, and more surface defects in nano-materials (Tiede et al., 2008). These physical and chemical properties of nano-materials could potentially change the biological effects and antimicrobial properties compared to its bulk materials.

\section{Nano-zinc}

A number of studies recently investigated the nano- $\mathrm{Zn}$ in the diets of animals as mineral supplements for better utilization of this mineral (Patra and Lalhriatpuii, 2019). Dietary zinc oxide $(\mathrm{ZnO})$, "generally regarded as safe", for long time and recently its nanoforms have been investigated in livestock as an antimicrobial growth promoter (Espitia et al., 2012). The antibacterial properties of $\mathrm{ZnO}$ were described as early as 1928 , when it was shown that pure $\mathrm{ZnO}$ and formulated $\mathrm{ZnO}$ (pressed into tablets and likely containing ZnO-NP) exhibited antibacterial properties against common skin microbes (Haxthausen and Rasch, 1928; Espitia et al., 2012). Due to the antimicrobial properties, $\mathrm{ZnO}$ is sometimes used to as a feed additive to reduce diarrhea incidence and improve the growth performance of animals (Cho et al., 2015). One study compared $0.6 \mathrm{~g} / \mathrm{kg} \mathrm{ZnO-}$ $\mathrm{NP}$ versus $2.0 \mathrm{~g} / \mathrm{kg}$ bulk $\mathrm{ZnO}$ on the performance of weaned piglets (Xia et al., 2017). Both $\mathrm{ZnO}$ formulations reduced the incidence of diarrhea associated with weaning; however, coarse $\mathrm{ZnO}-\mathrm{NP}$ reduced diarrhea incidence by approximately two folds more. This was possibly attributed to the greater than three-fold higher dose of coarse $\mathrm{ZnO}$ fed to piglets. It was demonstrated that the bacterial diversity increased in the ileum for the $\mathrm{ZnO}$-NP groups, but decreased in the cecum and colon (Xia et al., 2017). The relative abundances of Firmicutes, Lactobacillaceae and Lactobacillus dominated bacterial community at phylum, family and genus level, respectively, and their relative abundances were significantly decreased by supplementing nano- $\mathrm{ZnO}$ and/or traditional $\mathrm{ZnO}$. However, in treatments with nano- $\mathrm{ZnO}$ and bulk $\mathrm{ZnO}$, the abundances 
of Streptococcaceae, Bacillaceae, Streptococcus and Bacillus were observed to be markedly increased. The relative abundances of Proteobacteria, Halomonadaceae and Halomonas in the ZnO-NP treatment were significantly higher compared with the control group (Xia et al., 2017). Both nano- $\mathrm{ZnO}$ and traditional $\mathrm{ZnO}$ can enrich the bacterial richness and diversity in the gut, which may be beneficial to the construction of a more stable intestinal micro-ecosystem.

Enterohaemorrhagic Escherichia coli is an enteric pathogen that leads to diarrhea mediated by intestinal epithelial barrier disruptions during the weaning phase (Lu et al., 2014). Wang et al. (2017) reported that $250 \mathrm{mg} / \mathrm{kg} \mathrm{ZnO}-\mathrm{NP}$ did not affect the intestinal bacterial population in mice. The $E$. coli population in the large intestine was decreased when pigs were fed with $450 \mathrm{mg} /$ $\mathrm{kg} \mathrm{ZnO-NP}$ and $3000 \mathrm{mg} / \mathrm{kg} \mathrm{ZnO}$, but there was no difference between the $450 \mathrm{mg} / \mathrm{kg}$ $\mathrm{ZnO}-\mathrm{NP}$ and $3000 \mathrm{mg} / \mathrm{kg} \mathrm{ZnO}$ treatments (Pei et al., 2018). Also, dietary Zn-NP (5 $\mathrm{mg} / \mathrm{kg}$ ) increased the abundance of Clostridia by $15 \%$, and lowered the abundance of Bacilli by $15 \%$ in the class level, and decreased the abundances of Alistipes (by -5\%) and Lactobacillus (by $15 \%)$ and increased the abundances of Bacteroides in the genus level (Yausheva et al., 2018). Feng et al. (2017) indicated that abundances of Bacilli, Fusobacteria, and Proteobacteria were changed, and Lactobacillus abundance was reduced by $\mathrm{ZnO}-\mathrm{NP}$ in ileal digesta of hens. The antibacterial activity of $\mathrm{ZnO}$ has shown that it may lead to a shift in the composition of lactic acid bacteria and the pharmacological dosage of $\mathrm{ZnO}$ may lead to reduced ex vivo growth response of bacteria in weaned piglets (Wang et al., 2017; Liedtke et al., 2012).

The proposed mechanisms underlying $\mathrm{ZnO}$ NP-induced toxicity include the generation of reactive oxygen species causing oxidative stress (Dwivedi et al., 2014), reorganization of bacterial surface lipids/proteins (Liu et al., 2009) possibly due to electrostatic interactions (Espitia et al., 2012), and dissociation and release of individual $\mathrm{Zn}$ metal cations (Kasemets et al., 2009). Addition of $\mathrm{ZnO}-\mathrm{NP}$ in vitro caused nearcomplete inhibition of biofilm formation at the highest NP concentrations tested (Khan et al., 2013). The antibacterial effect of $\mathrm{ZnO}$ NP depends on dose, size, shape and other factors. Free $\mathrm{Zn}^{2+}$ may form highly soluble salts with chloride ions and reach the small intestine where it may exert a bactericidal effect. A study reported that the $\mathrm{Zn}^{2+}$ concentration of $\mathrm{ZnO}-\mathrm{NP}$ in simulated gastric fluid was six-fold higher than that of unprotected $\mathrm{ZnO}$, and high $\mathrm{Zn}^{2+}$ concentration can exert antimicrobial activity against $E$. coli (Barreto et al., 2017). Thus, a low concentration of ZnO-NP (450 $\mathrm{mg} \mathrm{kg} / \mathrm{diet}$ ) reduced the counts of $E$. coli and the incidence of post-weaning diarrhea, and improved intestinal integrity, and it was as efficient as $3000 \mathrm{mg} \mathrm{kg} / \mathrm{ZnO}$ (Pei et al., 2018).

\section{Nano-iron}

A few studies recently investigated the dietary nano-Fe as mineral supplements (Patra and Lalhriatpuii, 2019). Also, iron (Fe)-NP has been shown to be toxic to many commensal bacteria, including E. coli, 
Staphylococcus aureus and Bacillus subtilis (Touati, 2000; Qiu et al., 2018). The size, redox state, and concentration of $\mathrm{Fe}-\mathrm{NP}$ influence bacterial fate (Qiu et al., 2018). As with other metal oxides, $\mathrm{Fe}$ ions diffuse into the bacteria and induce the production of toxic reactive oxygen species (Touati, 2000; Auffan et al., 2008). Unlike other inorganic elements, $\mathrm{Fe}$ ions are known to enhance the growth and proliferation of many microbes, as it is an essential mineral for their growth (Ratledge and Dover, 2000). Oral supplementation with bulk Fe-sulfate caused marked shifts in microbial composition in rats (Dostal et al., 2012). Studies in humans have revealed that bulk iron increased the populations of enterobacteria and pathogenic E. coli and decreased the number of bifidobacteria, which led to intestinal inflammation symptoms mediated by the gut microbiota change (Jaeggi et al., 2015).

In a recent study, Fe-NP (iron hydroxideadipate tartrate) and Fe-sulfate were directly compared in humans for their bioavailability and effect on the microbiota. It was shown that the Fe from the NP was absorbed by about $80 \%$ as efficiently as the $\mathrm{Fe}$ from $\mathrm{Fe}$ sulfate. Supplementation with Fe-NP promoted diverse and healthy microbiota, allowing significant increase in the Lactobacillus populations, compared to bulk Fe (Pereira et al., 2014). In a follow up study, Fe salt changed the microbiota composition, whereas no differences were noted in the FeNP group (Pereira et al., 2015).

Dietary supplementation of Fe-NP at $8 \mathrm{mg} / \mathrm{kg}$ only caused insignificant changes in different microbiota in the cecum such as classes of Clostridia $(+4 \%)$ and Bacteroidia (+7\%), Bacilli (-10\%), which of families Lachnospiraceae $(+4 \%)$, Lactobacillaceae (-10\%), Bacteroidaceae $(+7 \%)$, Rikenellaceae $(+4 \%)$, and genus of Anaerotruncus (-2\%) and genus Lactobacillus (-10\%), Alistipes (+ 4\%), genus Bacteroides $(+7 \%)$ in poultry (Yausheva et al., 2018). Other authors also noted the slight antimicrobial activity of Fe-NP against Gram-negative and Grampositive microorganisms, including bacteria of class Bacilli (Arakha et al., 2015; Masadeh et al., 2015). These results indicate that $\mathrm{Fe}-\mathrm{NP}$ altered the microbiota to a lesser extent or sometimes improved beneficial microbiota in the gut, which are beneficial as opposed to bulk Fesulfate. This might offer a good approach to deliver supplementary iron without causing toxicity or compositional changes to the microbiota.

\section{Nano-silver}

Silver $(\mathrm{Ag})$ is a strong antimicrobial agent against a wide range of Gram-negative and Gram-positive bacteria including antibioticresistant strains, fungi or viruses and (Fröhlich and Fröhlich, 2016; Lara et al., 2010; Sawosz et al., 2011; Ahmed et al., 2016). Antibacterial property of Ag is wellknown for long time (Ahmed et al., 2016). Out of all the metals with antimicrobial properties, it was found that $\mathrm{Ag}$ has the most effective antibacterial action and is least toxic to animal cells (Ahmed et al., 2016). Silver is generally used in the nitrate form to induce antimicrobial effect, but Ag-NP have more antimicrobial properties due to its increased surface area. The presence of Ag$\mathrm{NP}$, even in low concentrations, exerts toxic 
properties on Acinetobacter, Escherichia, Pseudomonas, Salmonella, Vibrio, Bacillus, Clostridium, Enterococcus, Listeria, Staphylococcus, Streptococcus, methicillinresistant and vancomycin-resistant Staphylococcus aureus, and Enterococcus faecium in vitro (Morones et al., 2005; Kim et al., 2007; Wijnhoven et al., 2009; Ahmed et al., 2016). The antimicrobial activity of Ag-NP against Gram-positive and Gramnegative bacteria was also confirmed under in vivo conditions.

The subchronic administration of Ag-NP to rats $(9,18$ and $36 \mathrm{mg} / \mathrm{kg}$ body weight/day twice daily) for 13 weeks caused a shift in the gut microbiome towards a larger proportion of Gram negative bacteria, which was in turn linked to changes in the gut associated immune response (Williams et al., 2015). In ovo administration of AgNP in chickens reduced the counts of lactic acid bacteria and lactose-negative enterobacteria, but did not affect numbers of anaerobic, coliform bacteria, enterococci, and Clostridium perfringens in the ceca (Pineda et al., 2012). The reason for this is unknown, but it could be that the diverse species and numbers of microorganisms in live chickens contributed to the different responses of bacteria to Ag-NP under in vivo and in vitro conditions. Sawosz et al. (2007), however, reported no appreciable reduction in the number of colonies of bacteria kept under strict hygienic and biosecurity conditions. It has been suggested that AgNP would exhibit their greatest antimicrobial activity when birds are exposed to stressful conditions, e.g., when levels of pathogenic bacteria are high. Even Ag-NP $(50 \mathrm{mg} / \mathrm{kg}$ ) supplied with drinking water did not affect the microbial profile (Campylobacter jejuni, lactic acid bacteria, E. coli, Clostridium perfringenes, Enterococci, and lactose negative enterobacteria) of caecum, ileum and feces of boiler chickens infected with Campylobacter jejuni and (Vadalasetty et al., 2018). Antibacterial activity of Ag-NP against lactose-negative enterobacteria indicates that they could contribute to the control of Salmonella in poultry production, but the decreased numbers of lactic acid bacteria might not be favorable for development of beneficial probiotic bacteria (Pineda et al., 2012). In other study, lactic acid bacteria numbers (Lactobacillus salivarius and Lactobacillus fermentum), however, increased in the ceca of quails supplied with water $(5,15$ and $25 \mathrm{mg} / \mathrm{kg})$ containing hydrocolloidal Ag-NP at $25 \mathrm{mg} /$ $\mathrm{kg}$, although other bacteria such as E. coli, Enterobacter, Streptococcus bovis, Enterococcus faecium, and Bacteroides spp. (Sawosz et al., 2007). The reasons for these variations may reflect differences in the concentrations of Ag-NP, animal species, and dietary ingredients used in different studies. In this study, it was also noted that other undesirable bacteria such as Leuconostoc lactis and Actinomyces naeslundii increased at the high dose (25 $\mathrm{mg} / \mathrm{kg}$ ) of Ag-NP (Sawosz et al., 2007).

The effects of Ag-NP on gut microbiome are qualitatively different than those exerted by $\mathrm{Ag}$ ions, and are therefore probably not mediated (or only in part mediated) by the release of these ions (Das et al., 2014). In this study, the authors found that the human microbiota in stool samples was partially inhibited after $48 \mathrm{~h}$ exposure to $0-200 \mathrm{mg} / \mathrm{mL}$ of Ag-NP. A quantitatively similar antibacterial action was observed after exposure to $\mathrm{Ag}$ ions $(\mathrm{AgCl} ; 25-200 \mathrm{mg} / \mathrm{mL})$; 
however the effects were qualitatively different. An increase in body weight mediated by effects on gut flora composition has been observed in vivo in pigs exposed to $\operatorname{Ag}-\mathrm{NP}(0,20$ or $40 \mathrm{mg} / \mathrm{kg})$ that decreased intestinal coliform (Fondevila et al., 2009). In parallel, a dose-related decrease in intestinal coliforms was also observed.

The antimicrobial properties of Ag-NP depend on size, environmental conditions (size, $\mathrm{pH}$, ionic strength) and capping agent (Ahmed et al., 2016). The positive charge on the $\mathrm{Ag}$ ions is suggested vital for antimicrobial activities. $\mathrm{Ag}^{+}$ions (not unionized form) are able to form complexes with nucleic acids and preferentially interact with the nucleosides of nucleic acids. There is some literature showing the electrostatic attraction between positively charged NP and negatively charged bacterial cells (Ahmed et al., 2016). These NP have been shown to accumulate inside the membrane and can subsequently penetrate into the cells causing damage to cell wall or cell membranes. Silver atoms can also bind to thiol groups $(\mathrm{SH})$ of enzymes forming stable S-Ag bonds with thiol containing compounds leading to the deactivation of enzymes that involve in energy generation and ion transport (Ahmed et al., 2016; Qiu et al., 2018).

Gram-positive bacteria are less susceptible to $\mathrm{Ag}^{+}$than Gram-negative bacteria. The thicker bacterial wall of Gram-positive bacteria is supposed to better protect against toxicity of Ag-NP, as Gram-negative bacteria were more sensitive to toxicity of Ag-NP than Gram-positive bacteria (Lu et al., 2013). In this context, the difference of $\mathrm{ZnO}$ particle toxicity between Gram-positive and Gramnegative bacteria, however, was not pronounced (Toolabi et al., 2013). The greater sensitivity of Gram-negative bacteria may be explained not only by the thinner cell wall but also by the lower amount of the negatively charged peptidoglycan, which can trap the positively charged Ag ions (Kawahara et al., 2000). Bacteria growing under aerobic conditions were more sensitive to Ag-NP than anaerobe bacteria (Lu et al., 2013). It was speculated that higher sensitivity was due to higher oxidative dissolution of $\mathrm{Ag}$ particles. Other mechanisms involving interaction of $\mathrm{Ag}$ molecules with biological macromolecules such as enzymes and DNA through an electron-release mechanism or free radical production have also been proposed (Fröhlich and Fröhlich, 2016; Qiu et al., 2018).

The antibacterial effects of Ag-NP were tested on two commensal strains ( $L$. bulgaricus and $L$. casei) and two pathogenic strains (E. coli and S. aureus). Both Lactobacillus strains were more susceptible to Ag-NP, compared to the two pathogenic strains. It is proposed that Lactobacillus strains produce lactic acid and acidify the local microenvironment, which rapidly generates $\mathrm{Ag}$ ions and hydroxyl radicals from the Ag-NP. Generation of Ag ions and hydroxyl radicals promotes intracellular reactive oxygen species and oxidative stress, thus increasing cell death. This study outlines how the local $\mathrm{pH}$ microenvironment regulated by specific commensal microorganisms can create conditions that increase the antibacterial effects of Ag-NP (Tian et al., 2018). 


\section{Nano-titanium}

Most published studies on interactions between bacteria and $\mathrm{TiO}_{2}$ have focused essentially on $E$. coli and the antibacterial properties of nano- $\mathrm{TiO}_{2}$ in vitro (Kumar et al., 2011; Liu et al., 2010; Zhukova et al., 2012; Mercier-Bonin et al., 2018). The effects of $\mathrm{TiO}_{2}-\mathrm{NP}$ on the intestinal microbiota composition are limited. $\mathrm{TiO}_{2}-\mathrm{NP}$ exhibited toxicity against commensal intestinal microbes such as lactobacilli, enterobacteria, and Acetobacter species, in the absence of light in the in vitro conditions, but not in the in vivo conditions in drosophila (Liu et al., 2016). In another study, the exposure to $\mathrm{TiO}_{2}-\mathrm{NP}$ enabled the preservation of Proteobacteria populations and limited the proliferation of Firmicute population, compared to the changes in the control group (Waller et al., 2017). Some previous studies have implied that an abundance of Proteobacteria is associated with dysbiosis (Shin et al., 2015). The exposure of a gut microbial community from a healthy human donor to three different types of metal oxide NP ( $3 \mathrm{mg} / \mathrm{L} \mathrm{TiO}$, $0.01 \mu \mathrm{g} / \mathrm{L} \mathrm{ZnO}$, or $0.01 \mu \mathrm{g} / \mathrm{L} \mathrm{CeO}_{2}$ ) in a model colon for five days in the dark altered the phenotypic traits of the gut community, cell hydrophobicity, cell size, electrophoretic mobility of the cell wall and short-chain fatty acid production (Taylor et al., 2015). $\mathrm{TiO}_{2}-$ NP can induce both oxidative stress (i.e., generation of ROS and a decrease in glutathione level accompanied by an increase in lipid peroxidation) and damage to cell membrane and DNA structure causing inhibition of bacterial growth (Kumar et al., 2011; Liu et al., 2010). Electrostatic attraction could potentially occur between $\mathrm{TiO}_{2}-\mathrm{NP}$ and bacteria due to their opposite surface charges (Zhukova et al., 2012).

\section{Nano-copper}

A number of studies recently investigated the copper $(\mathrm{Cu})-\mathrm{NP}$ in the diets of animals as mineral supplements for its better absorption and animal performance (Patra and Lalhriatpuii, 2019). Also, $\mathrm{Cu}-\mathrm{NP}$ have also antibacterial actions against Grampositive and Gram-negative bacteria with the size and concentrations-dependent bactericidal effect (Ingle et al., 2014). Das et al. (2010) reported the antibacterial activity of CuO-NP against Staphylococcus aureus, Bacillus subtilis, and Escherichia coli. Among the different bacteria, Ramyadevi et al. (2012) reported that $E$. coli was the most susceptible bacterium followed by S.aureus, Micrococcus luteus, and Klebsiella pneumoniae, while Pseudomonas aeruginosa was found to be resistant to CuO-NP. E. coli and B. subtilis were completely inhibited at the concentration higher than $60 \mu \mathrm{g} / \mathrm{mL}$ of $\mathrm{Cu}-\mathrm{NP}$ (Yoon et al., 2007). Also, CuO-NP showed activity against a range of bacterial pathogens, including meticillin-resistant Staphylococcus aureus and E. coli, with minimum bactericidal concentrations ranging from 100 to $5000 \mu \mathrm{g} / \mathrm{mL}$ (Ren et al., 2009). The Gram-negative strains showed a greater susceptibility to CuO-NP (Ren et $a l ., 2009)$. The $\mathrm{CuO}-\mathrm{NP}$ have stronger antibacterial effects after Ag-NO or similar to Ag-NP (Yoon et al., 2007). While there are many studies on the in vitro antibacterial effects of $\mathrm{CuO}-\mathrm{NP}$, there are only few studies that investigated the antimicrobial effects in vivo. In pigs, $\mathrm{Cu}-$ loaded chitosan NP reduced $E$. coli but 
increased lactobacilli in the duodenum and jejunum (Wang et al., 2012). Dietary Cu NP $(1.7 \mathrm{mg} / \mathrm{kg}$ diet $)$ resulted in a slight decrease abundance of Firmicutes (9\%), and an increase in the abundance of Bacteroidetes (7\%), which was reflected by changes in decreased number of bacteria of genus Lactobacillus (by 9\%) and an increased number of representatives of genus Bacteroides (by 6\%), and genus Blautia (by 9\%) in cecal microbiota of broiler chickens (Yausheva et al., 2018). Many antibacterial mechanisms have been proposed such as interactions with - $\mathrm{SH}$ groups leading to protein denaturation, adsorption on the cell wall and cell membrane damaging the membrane and increasing the permeability, binding with DNA molecules, generation of reactive oxygen species, inactivation of the enzymes generating hydrogen peroxide, which cause bacterial cell death (Chang et al., 2012; Ingle et al., 2014). It has been reviewed that the reduced amount of negatively charged peptidoglycans would make Gram-negative bacteria less susceptible to positively charged antimicrobial NP (Ren et al., 2009).

\section{Nano-silica}

Silica-based nanomaterials have attracted great interest in biomedical applications due to their ease of synthesis and surface modification, and relatively inert chemical nature. One study reported that silica $\left(\mathrm{SiO}_{2}\right)$ $\mathrm{NP}$, compared to bulk $\mathrm{SiO}_{2}$, increased the inhibition of both commensal (E. coli and B. subtilis) and pathogenic (Pseudomonas fluorescens) microbes by more than two folds (Jiang et al., 2009). An in vivo study in mice investigated the use of $\mathrm{SiO}_{2}-\mathrm{NP}$ on the intestinal microbiota composition in mice. An almost two-fold increase was noted in the ratio of the Firmicutes/Bacteroidetes population because of $\mathrm{SiO}_{2}-\mathrm{NP}$ exposure (Chen et al., 2017); this increase in the ratio has been associated with obesity (Ley et al., 2006). Similar to the other inorganic NP, reactive oxygen species can be induced by $\mathrm{SiO}_{2}-\mathrm{NP}$, which can cause bacterial toxicity (Zhang et al., 2013).

\section{Other nanomaterials}

Many other nanomaterials, such as carbon nanotubes, gold and chitosan, have been investigated for the antimicrobial activities against intestinal commensal and pathogenic microorganisms in vitro. In an in vitro study, gut micro-organisms such as the Lactobacillus acidophilus, Escherichia coli, Staphylococcus aureus and Enterococcus fecalis were exposed to several types of carbon nanotubes at doses ranging from 20 to $100 \mu \mathrm{g} / \mathrm{L}$ and all carbon nanotubes showed a marked dosedependent anti-bacterial activity towards all the tested microbes (Chen et al., 2013). Furthermore, the shape of bacteria had also a role in their resistance, rod-shaped bacteria being more resistant than spherical ones to the injury. Zhu et al. (2014) found that exposure of $S$. aureus, Bacillus subtilis, E. coli, and Ochrobactrum sp. for $24 \mathrm{~h}$ at a concentration range of $10-50 \mathrm{mg} / \mathrm{L}$ of carbon nanotubes induced a dose dependent inactivation of the bacteria which was more marked for long carbon nanotubes in comparison to short and medium carbon nanotubes.

Gold nanoparticles (Au-NP) inhibited both Gram-positive and Gram-negative 
pathogens, including multi-drug-resistant pathogens and a structure-activity relationship was found as a function of Au-NP functionality (Li et al., 2014). Moreover, these Au-NP showed low toxicity to mammalian cells, and bacterial resistance was not noted after 20 generations (Li et al., 2014). Chitosan NP have shown promising against a wide range of pathogenic microorganisms including pathogenic $E$. coli $\mathrm{O} 157: \mathrm{H} 7$ in cattle (Ma et al., 2017).

\section{Toxicity of nano-materials}

Uptake of exogenous NP in the gastrointestinal tract is greater than microparticles. It has been suggested that NP can usually bypass normal physiological pathways of nutrient transport through cell membranes and distribution in tissues (Patra and Lalhriatpuii, 2019). Uptake of nutrient along with NP may occur by passive diffusion through the mucosal cells, by means of active transport mechanisms and paracellular pathways (Patra et al., 2019b). Many studies have reported that $\mathrm{ZnO}-\mathrm{NP}$ are toxic to Caco-2 cell (human colon epithelial cells) culture causing oxidative damage (Cao et al., 2015). Similarly, CuO-NP, carbon nanotubes, and manganese oxide NP also showed toxic effects on the Caco-2 cells (Nguyen et al., 2015; Titma et al., 2016). Nano-Ag can induce various toxic effects with different intensities. The NP systemically distributed in different target organs such as liver, spleen, lung, and kidney and, in some cases, the heart, where they can induce general cytotoxicity, increased oxidative stress, decreased mitochondrial activity, and apoptosis (Vandebriel and Jong, 2012). Although these mineral NP exert toxic effect on the tissue cells at high concentrations, a long time supplementation of mineral NP to animals may result in toxicity at a lower dose. Therefore, the toxicity and safety levels of the each type of NP should be assessed in animals with period of experiment before they can be recommended in animal feeding. Therefore, a net balance between these two potentially opposite actions should always be considered when considering any NP for microbiota-mediated effects.

\section{Conclusions}

Several nanomaterials have in vitro and in vivo broad spectrum antimicrobial effects. There are numerous studies on the antimicrobial properties on nanomaterials in the in vitro conditions, but studies on their effects in vivo conditions are limited. It seems many nanomaterials can inhibit the growth of both pathogenic as well as beneficial commensal gut microbiota, and this may also cause dysbiosis in the gut due to overgrowth of undesirable bacteria. The inhibitory mechanisms on the bacterial growth are not well-defined and different mineral NP exert diverse mode of actions. A structure-activity relationship is present for the antimicrobial effects of NP, which requires a proper design for preparation of effective antimicrobial NP. Although NP have promising effect against the pathogenic microorganism, they can potentially induce toxicity problems at higher doses. The toxicity of some kind of NP to mammalian cells is low, but they have greater antimicrobial activities against microbes. A net balance between these two opposite functions of NP needs to be considered for practical application of NP as antimicrobial feed additives. Nano-forms of essential 
minerals could serve advantages such as reduced concentrations in diets for optimal performance and health of animals lowering the environmental pollution and antimicrobial feed additives. Overall, in vitro studies suggest that nanoparticles are promising antimicrobial agents, the studies

\section{REFERENCES}

Ahmed S, Ahmad M, Swami BL and Ikram S, 2016. A review on plants extract mediated synthesis of silver nanoparticles for antimicrobial applications: A green expertise. J Adv Res, 7: 17-28

Arakha M, Pal S, Samantarrai D, Panigrahi TK, Mallick BC et al., 2015. Antimicrobial activity of iron oxide nanoparticle upon modulation of nanoparticle-bacteria interface. Sci Rep, 5: 14813

Auffan M, Achouak W, Rose J, Roncato MA, Chanéac C et al., 2008. Relation between the redox state of iron-based nanoparticles and their cytotoxicity toward Escherichia coli. Environ Sci Technol, 42: 6730-6735

Barreto MSR, Andrade CT, da Silva L, Cabral LM, Paschoalin VMF et al., 2017. In vitro physiological and antibacterial characterization of $\mathrm{ZnO}$ nanoparticle composites in simulated porcine gastric and enteric fluids. BMC Vet Res, 13: 181

Cao Y, Roursgaard M, Kermanizadeh A, Loft S and Møller P, 2015. Synergistic effects of zinc oxide nanoparticles and fatty acids on toxicity to caco-2 cells. Int $\mathrm{J}$ Toxicol, 34 : 67-76 on livestock species to use as antimicrobial growth promoters are scarce. More studies are required to recommend the nanomaterials as new generation antimicrobial feed additives in farm animals as a substitute of in-feed antibiotics and other antimicrobial agents.

Chang YN, Zhang M, Xia L, Zhang J and Xing G, 2012. The toxic effects and mechanisms of $\mathrm{CuO}$ and $\mathrm{ZnO}$ nanoparticles. Materials, 5: 2850-2871

Chen H, Wang B, Gao D, Guan M, Zheng L et al., 2013. Broad-spectrum antibacterial activity of carbon nanotubes (CNTs) to human gut bacteria. Small, 9: 2735-2746

Chen HQ, Zhao RF, Wang B, Cai CX, Zheng LN et al., 2017. The effects of orally administered $\mathrm{Ag}, \mathrm{TiO}_{2}$ and $\mathrm{SiO}_{2}$ nanoparticles on gut microbiota composition and colitis induction in mice. NanoImpact, 8: 80-88

Cho JH, Upadhaya SD and Kim IH, 2015. Effects of dietary supplementation of modified zinc oxide on growth performance, nutrient digestibility, blood profiles, fecal microbial shedding and fecal score in weanling pigs. Anim Sci J, 86: 617-623

Das P, McDonald JAK, Petrof EO, Allen-Vercoe E and Walker VK, 2014. Nanosilver-mediated change in human intestinal microbiota. J Nanosci Nanotechnol, 5: 5

Das R, Gang S, Nath SS and Bhattacharjee R, 2010. Linoleic acid capped copper 
nanoparticles for antibacterial activity. J Bionanosci, 4: 82-86

Dostal A, Chassard C, Hilty FM, Zimmermann MB, Jaeggi $\mathrm{T}$ et al., 2012. Iron depletion and repletion with ferrous sulfate or electrolytic iron modifies the composition and metabolic activity of the gut microbiota in rats. J Nutr, 142: $271-277$

Dwivedi S, Wahab R, Khan F, Mishra YK, Musarrat J et al., 2014. Reactive oxygen species mediated bacterial biofilm inhibition via zinc oxide nanoparticles and their statistical determination. PLoS One, 9: e111289

Espitia PJP, Soares NFF, dos Reis Coimbra JS, de Andrade NJ, Cruz RS et al., 2012. Zinc oxide nanoparticles: Synthesis, antimicrobial activity and food packaging applications. Food Bioprocess Technol, 5: 1447-1464

Feng Y, Min L, Zhang W, Liu J, Hou Z et al., 2017. Zinc oxide nanoparticles influence microflora in ileal digesta and correlate well with blood metabolites. Front Microbiol, 8: 992

Fondevila M, Herrer R, Casalbas MC, Abecia L and Ducia JJ, 2009. Silver nanoparticles as a potential antimicrobial additive for weaned pigs. Anim Feed Sci Technol, 150: 259-269

Fröhlich EF and Fröhlich E, 2016. Cytotoxicity of nanoparticles contained in food on intestinal cells and the gut microbiota. Int J Mol Sci, 17: 509

Gopi M, Pearlin B, Kumar RD, Shanmathy M and Prabakar G, 2017. Role of nanoparticles in animal and poultry nutrition: modes of action and applications in formulating feed additives and food processing. Int $\mathbf{J}$ Pharmacol, 13: 724-731
Haxthausen H and Rasch C, 1928. Some remarks on the bactericidal properties of zinc oxide. Br J Dermatol 40: 497-501

Ingle AP, Duran N and Rai M, 2014. Bioactivity, mechanism of action, and cytotoxicity of copper-based nanoparticles: A review. Appl Microbiol Biotechnol, 98: 1001-1009

ISO, 2015. ISO/TS 80004-2:2015(en). Nanotechnologies. Vocabulary, Part 2: Nano-objects. https://www.iso.org/ obp/ui/ \#iso:std:iso:ts:80004:-2:ed-1:v1:en:sec:3.5.

Jaeggi T, Kortman GA, Moretti D, Chassard C, Holding $\mathrm{P}$ et al.., 2015. Iron fortification adversely affects the gut microbiome, increases pathogen abundance and induces intestinal inflammation in Kenyan infants. Gut, 64: 731-742

Jiang W, Mashayekhi H and Xing BS, 2009. Bacterial toxicity comparison between nanoand micro-scaled oxide particles. Environ Pollut, 157: 1619-1625

Kasemets K, Ivask A, Dubourguier HC and Kahru A, 2009. Toxicity of nanoparticles of $\mathrm{ZnO}$, $\mathrm{CuO}$ and $\mathrm{TiO}_{2}$ to yeast Saccharomyces cerevisiae. Toxicol In Vitro, 23: 1116-1122

Kawahara K, Tsuruda K, Morishita M and Uchida M, 2000. Antibacterial effect of silver-zeolite on oral bacteria under anaerobic conditions. Dent Mater, 16: 452-455

Khan ST, Ahamed M, Al-Khedhairy A and Musarrat J, 2013. Biocidal effect of copper and zinc oxide nanoparticles on human oral microbiome and biofilm formation. Mater Lett, 97: 67-70

Kim JS, Kuk E, Yu KN, Kim JH, Park SJ et al.., 2007. Antimicrobial effects of silver 
nanoparticles. Nanomedicine, 3: 95-101

Kumar A, Pandey AK, Singh SS, Shanker R and Dhawan A, 2011. Engineered $\mathrm{ZnO}$ and TiO (2) nanoparticles induce oxidative stress and DNA damage leading to reduced viability of Escherichia coli. Free Radic Biol Med, 51: 1872-1881

Lara HH, Ayala-Nunez NV, Ixtepan Turrent L and Rodriguez Padilla C, 2010. Bactericidal effect of silver nanoparticles against multidrug-resistant bacteria. World J Microbiol Biotechnol, 26: 615-621

Ley RE, Turnbaugh PJ, Klein S and Gordon JI, 2006. Microbial ecology: Human gut microbes associated with obesity. Nature, 444: 10221023

Li X, Robinson SM, Gupta A, Saha K, Jiang Z et al., 2014. Functional gold nanoparticles as potent antimicrobial agents against multidrug-resistant bacteria. ACS Nano, 8: 1068210686

Liedtke $\mathrm{J}$ and Vahjen $\mathrm{W}, 2012$. In vitro antibacterial activity of zinc oxide on a broad range of reference strains of intestinal origin. Vet Microbiol, 160: 251-255

Liu LY, Sun L, Zhong ZT, Zhu J and Song HY, 2016. Effects of titanium dioxide nanoparticles on intestinal commensal bacteria. Nucl Sci Techniq, 27: 5

Liu Y, He L, Mustapha A, Li H, Hu ZQ et al., 2009. Antibacterial activities of zinc oxide nanoparticles against Escherichia coli O157:H7. J Appl Microbiol, 107: 1193-1201

Liu P, Duan W, Wang Q and Li X, 2010. The damage of outer membrane of Escherichia coli in the presence of $\mathrm{TiO}_{2}$ combined with
UV light. Colloids Surf B Biointerfaces, 78: 171-176

Lu RY, Yang WX and Hu YJ, 2014. The role of epithelial tight junctions involved in pathogen infections. Mol Biol Rep, 41: 6591-6610

Lu Z, Rong K, Li J, Yang H and Chen R, 2013. Size-dependent antibacterial activities of silver nanoparticles against oral anaerobic pathogenic bacteria. J Mater Sci Mater Med, 24: $1465-1471$

Ma Z, Garrido-Maestu A and Jeong KC, 2017. Application, mode of action, and in vivo activity of chitosan and its micro- and nanoparticles as antimicrobial agents: A review. Carbohydr Polym, 176: 257-265

Masadeh MM, Karasneh GA, Al-Akhras MA, Albiss BA, Aljarah KM et al., 2015. Cerium oxide and iron oxide nanoparticles abolish the antibacterial activity of ciprofloxacin against Gram positive and Gram negative biofilm bacteria. Cytotechnology, 67: 427435

Mercier-Bonin M, Despax B, Raynaud P, HoudeauE and Thomas M., 2018. Mucus and microbiota as emerging players in gut nanotoxicology: The example of dietary silver and titanium dioxide nanoparticles. Crit Rev Food Sci Nutr, 58: 1023-1032

Mittal AK, Chisti Y and Banerjee UC, 2013. Synthesis of metallic nanoparticles using plant extracts. Biotechnol Adv, 31: 346-356

Morones JR, Elechiguerra JL, Camacho A, Holt K, Kouri JB et al., 2005. The bactericidal effect of silver nanoparticles. Nanotechnology, 16: 2346-2353 
Nguyen TH, Lin M and Mustapha A, 2015. Toxicity of graphene oxide on intestinal bacteria and Caco-2 cells. J Food Prot, 78: 996-1002

Patra AK, 2018. Interactions of plant bioactives with nutrient transport systems in gut of livestock. Indian J Anim Hlth, 57: 125-136

Patra AK, Geiger S, Braun HS and Aschenbach JR, 2019a. Dietary supplementation of menthol-rich bioactive lipid compounds alters circadian eating behaviour of sheep. BMC Vet Res, 15: 352

Patra AK, Amasheh S and Aschenbach JR, 2019b. Modulation of gastrointestinal barrier and nutrient transport function in farm animals by natural plant bioactive compounds - A comprehensive review. Crit Rev Food Sci Nutr, 59: 3237-3266

Patra AK and Lalhriatpuii M, 2019. Progress and prospect of essential mineral nanoparticles in poultry nutrition and feeding - A review. Biological Trace Elem Res, doi: 10.1007/ s12011-019-01959-1

Pei X, Xiao Z, Liu L, Wang G, Tao W et al., 2019. Effects of dietary zinc oxide nanoparticles supplementation on growth performance, zinc status, intestinal morphology, microflora population, and immune response in weaned pigs. J Sci Food Agric, 99: 13661374

Pereira DIA, Aslam MF, Frazer DM, Schmidt A, Walton GE et al., 2015. Dietary iron depletion at weaning imprints low microbiome diversity and this is not recovered with oral nano $\mathrm{Fe}(\mathrm{III})$. Microbiol Open, 4: 12-27

Pereira DIA, Bruggraber SFA, Faria N, Poots LK, Tagmount MA et al., 2014. Nanoparticulate
iron(III) oxo-hydroxide delivers safe iron that is well absorbed and utilised in humans. Nanomed: Nanotechnol Biol Med, 10: 18771886

Pineda L, Sawosz E, Lauridsen C, Engberg RM, Elnif $\mathrm{J}$ et al., 2012. Influence of in ovo injection and subsequent provision of silver nanoparticles on growth performance, microbial profile, and immune status of broiler chickens. Open Access Anim Physiol, 4: $1-8$

Qiu K, Durham PG and Anselmo AC, 2018. Inorganic nanoparticles and the microbiome. Nano Res, 11: 4936-4954

Ramyadevi J, Jeyasubramanian K, Marikani A, Rajakumar G and Rahuman AA, 2012. Synthesis and antimicrobial activity of copper nanoparticles. Mater Lett, 71: 114116

Ratledge C and Dover LG, 2000. Iron metabolism in pathogenic bacteria. Ann Rev Microbiol, 54: $881-941$

Ren G, Hu D, Cheng EWC, Vargas-Reus MA, Reip P et al., 2009 Characterization of copper oxide nanoparticles for antimicrobial applications. Int $\mathrm{J}$ Antimicrob Agents, 33: 587-590

Sawosz E, Binek M, Grodzik M, Zieliñska M, Sysa $\mathrm{P}$ et al., 2007. Influence of hydrocolloidal silver nanoparticles on gastrointestinal microflora and morphology of enterocytes of quails. Arch Anim Nutr, 61: 444-451

Sawosz E, Chwalibog A, Mitura K, Mitura S, Szeliga J et al., 2011. Visualisation of morphological interaction of diamond and silver nanoparticles with Salmonella enteritidis and Listeria monocytogenes. J Nanosci Nanotechnol, 11: 7635-7641 
Shin NR, Whon TW and Bae JW, 2015. Proteobacteria: Microbial signature of dysbiosis in gut microbiota. Trends Biotechnol, 33: 496-503

Swain PS, Rajendran D, Rao SBN and Dominic G, 2015. Preparation and effects of nano mineral particle feeding in livestock: A review. Vet World, 8: 888-891

Taylor A A, Marcus IM, Guysi RL and Walker SL, 2015. Metal oxide nanoparticles induce minimal phenotypic changes in a model colon gut microbiota. Environ Eng Sci, 32: 602-612

Tian X, Jiang XM, Welch C, Croley TR, Wong TY et al., 2018. Bactericidal effects of silver nanoparticles on lactobacilli and the underlying mechanism. ACS Appl Mater Interfaces, 10: 8443-8450

Tiede K, Boxall ABA, Tear SP, Lewis J, Davis H et al., 2008. Detection and characterization of engineered nanoparticles in food and the environment. Food Addit Contam Part A Chem Anal Control Expo Risk Assess, 25: 795-821

Titma T, Shimmo R, Siigur J and Kahru A, 2016. Toxicity of antimony, copper, cobalt, manganese, titanium and zinc oxide nanoparticles for the alveolar and intestinal epithelial barrier cells in vitro. Cytotechnology, 68: 2363-2377

Toolabi A and Khanjani N, 2013. Evaluating the toxicity of zinc oxide nanoparticles on the dominant bacteria in the sludge of wastewater treatment facilities. Adv Environ Biol, 7: 812-816

Touati D, 2000. Iron and oxidative stress in bacteria. Arch Biochem Biophys, 373: 1-6
Vadalasetty KP, Lauridsen C, Engberg RM, Vadalasetty R, Kutwin M et al., 2018. Influence of silver nanoparticles on growth and health of broiler chickens after infection with Campylobacter jejuni. BMC Vet Res, 14: 1

Vandebriel R and de Jong W, 2012. A review of mammalian toxicity of $\mathrm{ZnO}$ nanoparticles. Nanotechnol Sci Appl, 5: 61-71

Waller T, Chen C and Walker SL, 2017. Food and industrial grade titanium dioxide impacts gut microbiota. Environ Eng Sci, 34: 537-550

Wang C, Cheng K, Zhou L, He J, Zheng X et al., 2017. Evaluation of long-term toxicity of oral zinc oxide nanoparticles and zinc sulfate in mice. Biol Trace Elem Res, 178: 276-282

Wang MQ, Du YJ, Wang C, Tao WJ, He YD et al., 2012. Effects of copper-loaded chitosan nanoparticles on intestinal microflora and morphology in weaned piglets. Biol Trace Elem Res, 149: 184-189

Wijnhoven SWP, Peijnenburg WJGM, Herberts CA, Hagens WI, Oomen AG et al.., 2009. Nanosilver - A review of available data and knowledge gaps in human and environmental risk assessment. Nanotoxicology, 3: 109-138

Williams K, Milner J, Boudreau MD, Gokulan K, Cerniglia CE et al., 2015. Effects of subchronic exposure of silver nanoparticles on intestinal microbiota and gutassociated immune responses in the ileum of SpragueDawley rats. Nanotoxicology, 9: 279-289

Xia T, Lai WQ, Han MM, Han M, Ma X et al., 2017. Dietary $\mathrm{ZnO}$ nanoparticles alters intestinal microbiota and inflammation response in weaned piglets. Oncotarget, 8: 64878-64891 
Yang J, Deivaraj TC, Too HP and Lee JY, 2004. Acetate stabilization of metal nanoparticles and its role in the preparation of metal nanoparticles in ethylene glycol. Langmuir, 20: $4241-4245$

Yausheva A, Miroshnikov S and Sizova A, 2018. Intestinal microbiome of broiler chickens after use of nanoparticles and metal salts. Environ Sci Pollut Res, 25: 18109-18120

Yoon KY, Byeon JH, Park JH and Hwang J, 2007. Susceptibility constants of Escherichia coli and Bacillus subtilis to silver and copper nanoparticles. Sci Total Environ, 373: $572-575$
Zhang W, Li Y, Niu JF and Chen YS, 2013. Photogeneration of reactive oxygen species on uncoated silver, gold, nickel, and silicon nanoparticles and their antibacterial effects. Langmuir, 29: 4647-4651

Zhu B, Xia X, Xia N, Zhang S and Guo X, 2014. Modifications of fatty acids in the membranes of bacteria: implications for an adaptative mechanism to the toxicity of carbon nanotubes. Environ Sci Technol, 48: 4086-4095

Zhukova LV, Kiwi J and Nikandrov VV, 2012. $\mathrm{TiO}_{2}$ nanoparticles suppress Escherichia coli cell division in the absence of UV irradiation in acidic conditions. Colloids Surf B Biointerfaces, 97: 240-247 